\title{
Economics of Recycling and Recovery
}

\author{
Odysseas N. Kopsidas, Stephanos D. V. Giakoumatos
}

University of Piraeus, School of Maritime and Industrial Studies, Karaoli \& Dimitriou 80, Piraeus, Greece

Email: odykopsi@yahoo.gr, sgiakou@hotmail.com, sgiakoum@webmail.unipi.gr

How to cite this paper: Kopsidas, O.N. and Giakoumatos, S.D.V. (2021) Economics of Recycling and Recovery. Natural Resources, 12, 73-90.

https://doi.org/10.4236/nr.2021.124007

Received: March 4, 2021

Accepted: April 13, 2021

Published: April 16, 2021

Copyright $\odot 2021$ by author(s) and Scientific Research Publishing Inc. This work is licensed under the Creative Commons Attribution International License (CC BY 4.0).

http://creativecommons.org/licenses/by/4.0/

\begin{abstract}
In the below-given paper, a holistic, multidisciplinary approach of goods consumption, the economics of recycling and recovery is unfolding, concisely structured, until 2013. The analysis was focused, in brief, on some economic models addressed to environmental issues, tax policies, welfare, waste management, and specifically on recycling and reuse economic modelling. Recycle is an established practice in many countries, while reuse is still under development. Reuse in many aspects is a more desirable option, as far as waste management concerns, and EU legislation seems to encourage this practice. Many industries, especially in the technology section, have developed recycle and reuse programs in order to gain an advantage, while some of them have set a target of zero waste in their production process.
\end{abstract}

\section{Keywords}

Recycling, Reuse, Consumption, Environmental, Zero Waste

\section{Introduction}

Economic activities of mankind were always fast bound to environmental impacts. In the course of history, resources were overexploited and transformed into energy, numerous consumption goods and various commodities. Raw materials under certain circumstances e.g. war campaigns, were faced with depletion, for instance (timber/mining ore exploitation) etc. and transformed into economic goods. In this perpetual process of transformation, the gradual environmental degradation seems to be inevitable.

\section{Environment and Economics}

\subsection{An Economic Approach to the Environment}

Environmental problems resulted from the constant economic activity are, in general, extremely complex and varied. Scorse (2010) [1] identifies three severe 
sources that cause these problems i.e.:

$>$ The market failure. The price of a product fails to reflect the true production cost. The environmental impact of a unit to be produced is not included in the production cost so as to pass to the final consumers/buyers. As a result, the whole production chain causes "externalities". Beyond externalities there is a lack of information about good products and services and incomplete and/or nontransparent distribution of property rights.

$>$ The tragedy of the commons.

The under-provisioning of public goods.

It's worthwhile having a deeper introspect of the first cause. Thus, in order to overcome the pre-described market failure, there must be a proper evaluation of the environment. This entails proper assessment of negative externalities due to all human activities which undermine the natural capital and natural benefits delivered to humankind. As such, are ecosystem services; the provision of clean air, water, food, fibers, soil fertility, species diversity, soft climate and natural habitats; crop pollination; carbon sequestration; and decomposition of wastes. In this direction, cost-benefit analysis (CBA) could be an indispensable tool for decision making and policy design [2].

Over time, as environmental policies are becoming even more complex and challenging (e.g. global warming, biodiversity reduction, health impacts due to water and air pollution), more and more countries are introducing legal provisions requiring impact and cost-benefit assessments through their major policies' implementation and regulations [2].

Besides CBA, various other environmental evaluation techniques have been emerged over the years, mostly as alternative appraisal methods. However, CBA is considered to be the most comprehensive procedure among the following listed:

* Environmental Impact Assessment (EIA) or Environmental Assessment (EA).

- Strategic Environmental Assessment (SEA).

* Life Cycle Analysis (LCA).

* Risk Assessment (RA).

* Comparative Risk assessment (CRA).

* Risk-Benefit Analysis (RBA).

* Risk-Risk Analysis (RRA).

* Health-Health Analysis (HHA)

* Cost-Effectiveness Analysis (CEA).

* Multi-Criteria Analysis (MCA).

\subsection{Tax Policies to Address Environmental Problems}

Economists have developed certain policy options for addressing environmental problems. There are two main market-based instruments as "regulators" for reducing greenhouse gases (GHG) emissions; 1) the cap-and-trade system and 2) the GHG (carbon) tax. 
Cap-and-trade was introduced to the industrial market as an innovative policy at that time, to provide economic motives for achieving GHG emission reduction [3].

The definition given from Stavins (2003) for the afore-mentioned approach is the following presented [4]:

"Under a tradable permit system, an allowable overall level of pollution is established and allocated among firms in the form of permits. Firms that keep their emission levels below their allotted level may sell their surplus permits to other firms or use them to offset excess emissions in other parts of their facilities."

A tax imposed on greenhouse gases (GHGs) is a "Pigovian tax" that can be used to achieve a cost-effective reduction in GHG as a whole and not particularly upon $\mathrm{CO}_{2}$ emissions. Similarly, GHG taxes use the power of market price trends to encourage GHG emission reduction from a variety of production source.

According to Scorce (2010), these policies are not controversial at first glance, in terms of theoretical standpoint; Problems emerge upon implementation and surely in the details to start running properly. Both, GHGs taxes and capand-trade system are subjected to political compromises which could seriously undermine the effectiveness of the outcome [1].

\subsection{Welfare and Environment}

Undoubtedly, industrial progress incurs environmental degradation which is considered to be unavoidable. The question though that arises is stated as "how much is the impact of environmental damage to well-being". To answer this question in a persuasive manner, economists [5] introduced the Measure of Economic Welfare (MEW).

MEW takes GDP as a starting point and is adjusted to the value of leisure time and the amount of unpaid work (positive impact), as well as the value of the environmental damage caused by industrial production and consumption (negative impact). Daly and Cobb (1989) developed a broader macroeconomic index based on MEW [6] i.e. the Index of Sustainable Economic Welfare (ISEW), to overcome, e.g. values of household labor that GNP excludes it, which spans economic, social and environmental dimensions. ISEW adjusted national accounting practices to encompass a broader set of welfare determinants, which include deductions for military spending, environmental degradation and depreciation in natural capital. Computation of an ISEW usually starts from the value of personal consumption expenditures which is a sub-component of GDP. A characteristic example was presented by a U.S. study [7]. According to them, weighted personal consumption expenditures were taken into account in which were added household labor estimates. Furthermore, net private investment was added and the placement of U.S. net international investment position. Many of expenditures regarding health, education and defense were subtracted, as well as estimates of commuting, car accidents, water \& air environmental degradation, 
noise pollution, loss of wetlands and farmlands, non-renewable resources depletion and long-term environmental damages due to greenhouse $\mathrm{CO}_{2}$ emissions. The ISEW is simply the sum of the weighted personal consumption expenditures incorporating all the mentioned corrections [8].

\subsection{Waste Management}

Significant concerns over the environmental impact of waste have emerged in recent decades. Managing waste has a wide range of potential environmental impacts. These impacts depend upon the amount and composition of waste streams as well as on the methods adopted for treating them (landfilling, incineration etc.). Improper waste management in numerous cases incurs soil and groundwater contamination, threatening the natural ecosystems and the health of the exposed population [9].

Other problems related to the waste management are the existing disposal facilities, which are at the end of their operational design and cannot be expanded further-reaching saturation. The determination and establishment of new landfill locations or even incineration plants are intercepted by the local protest movements due to the widespread belief of the local communities, in many parts of Europe, that the negative impact of such an establishment will surely affect the environment and the health of the dwellers at a close distance. The increased movement of waste, both within and outside the EU, needs to be carefully monitored for the risk posed to human health and to the environment by some waste stream shipments [10].

Two major "green" waste management options that seem to be the only viable and sustainable solutions, in terms of energy saving, and environmental friendliness is the "recycling" and the "reuse". Reuse differs from recycling in the fact that there's no need to change the physical properties of the material. Consequently, reuse is more energy efficient in contrast with recycling.

A survey undertaken by the Chartered Institution of Wastes Management [11], revealed that waste prevention and reuse strategies are considered to be the number one issue to address for professionals in the Waste Management Industry. According to CIWM, people's behavior is critical to achieve waste prevention, as the concepts of prevention and reuse are less tangible and more difficult to grasp and adopt, compared to recycling or composting activities.

\section{Recycling}

\subsection{Economic Approaches on Recycle}

Recycling is a process, where used, discarded materials (waste) are transformed into new products in order to achieve the reduction of raw materials consumption, energy usage and air/water pollution (avoiding incineration or landfilling). According to the U.S. Environmental Protection Agency (EPA), "Recycling (including composting) is the preferred waste management option to further reduce potential risks to human health and the environment, divert waste from 
landfills and combustors, conserve energy, and slow the depletion of nonrenewable natural resources".

Recycled content is defined by ISO 14021 (International Organization of Standardization). It is the ... proportion, by mass, of recycled material in a product or packaging ... Thereof, only pre-consumer and post-consumer materials shall be considered as recycled content, consistent with the following usage of the term [12].

Pre-consumer material is considered to be the material diverted from the waste stream during a manufacturing process. Excluded is the reutilization of materials such as rework, regrind or scrap generated in a process and capable of being reclaimed within the same process that generated it.

Post-consumer material regards the material generated by households or by commercial, industrial or even institutional facilities in their role as end-users of the product. That material can no longer be used for its intended purpose

Several articles modeled the economics of recycling from different stakeholders' standpoint, however, there are still a lot of issues to be settled until a consensus to be achieved among them [13]. By examining all the feasible optimal solutions under certain constraints, such as the quality demand and some other criteria such as the environmental impact, a consensus statement or collaborative decision making, among stakeholders could be reached.

A general model for evaluating the economic and environmental performance of electronics recycling systems is developed [14]. This model comprehends the three main functions in a recycling system-collection, processing, and system management and aims to enable quantification of the impact of the activity and penetrate to the system structure of electronics' recycling systems performance. Different modeling techniques are used ad hoc, including process-based cost models, to evaluate the economic performance, and life cycle assessment tools, to evaluate the environmental performance.

Various models incorporate different techniques, including logistics models to evaluate collection procedure, end-of-life treatment models to evaluate product route processing, even process-based cost models to evaluate collection and processing economics. All the above methods can be used to evaluate the economic performance of a recycling system, whereas other methods, such as life cycle assessment (LCA), can be used to evaluate the environmental impact performance.

Integrated Sustainable Waste Management (ISWM) allows studies of complex and multi-dimensional systems in an integral way [15]. The model was developed at the beginning by waste consultants of urban environment and development and partners or organizations working in developing countries in the mid-1980s. It was further developed by the Collaborative Working Group (CWG) on solid waste management in the mid 1990s.

The model acknowledges the importance of three-dimensional analysis and developing or changing the waste management system. The defined dimensions are: 
1) The stakeholders that have an interest in solid waste management;

2) The elements or stages of the movement or flow of materials from the generation points towards treatment and;

3) Final disposal and the aspects of "lenses" through which the system is analyzed.

\subsection{Benefits and Costs of Recycling}

In order to form a complete perspective of the benefits and costs of recycling, a cost-benefit analysis was demonstrated in a schematic drawing. The benefits are estimated as landfill savings (landfill operational cost), externalities and the saved costs of collection for disposal (Figure 1).

Costs of recycling are estimated from the costs of collection and sorting, minus the value of material in end-use markets.

It has traditionally been argued that recycling municipal solid waste (MSW) is not economically viable \& recycling processing is not worthwhile from a social point of view [16], unless externalities, long-term dynamic considerations and the entire product life cycle are taken into account.

It was pointed out that by exploiting merely a waste percentage of $51 \%$ of the municipalities, it would be efficient to adopt recycling as a cost-efficient strategy, even without accounting for externality costs. Recycling of municipalities' wastes incurs cost reduction by an average of $11 \%$ [17].

\subsection{Future Prospects of Recycling}

According to the EU report regarding the Thematic Strategy on the Prevention and Recycling of Waste, some interesting predictions and future guidelines of recycling were announced. The ever-growing population combined with stronger emerging economies lead to a total consumption increment which will increase the pressure on all resource uses in particular, related to biotic materials, minerals and metals, affecting the environment and health impact. Thereof the demand for raw materials in the EU will continue to grow, and given the EU dependence on the importation of many raw materials, the role of recycling will become even more important [3].

REACH Regulation [18] already contributed to reducing hazardous waste generation aiming at a higher percentage of biowaste diversion from landfilling offering new energy content exploitation alternatives for composting and gas production.

On top of the expected effects as an outcome of e.g. Landfill Directive implementation [19], prevention strategies and upgraded recycling systems could lead to additional significant benefits. Full implementation of EU waste legislation and increased prevention and recycling could lead to additional GHG emission reduction corresponding to a significant part of the European climate reduction targets. Recycling will continue to offer economic opportunities whilst contributing to the resource efficiency of the EU economy, apart from the expected new job openings in the waste recycling sector. 


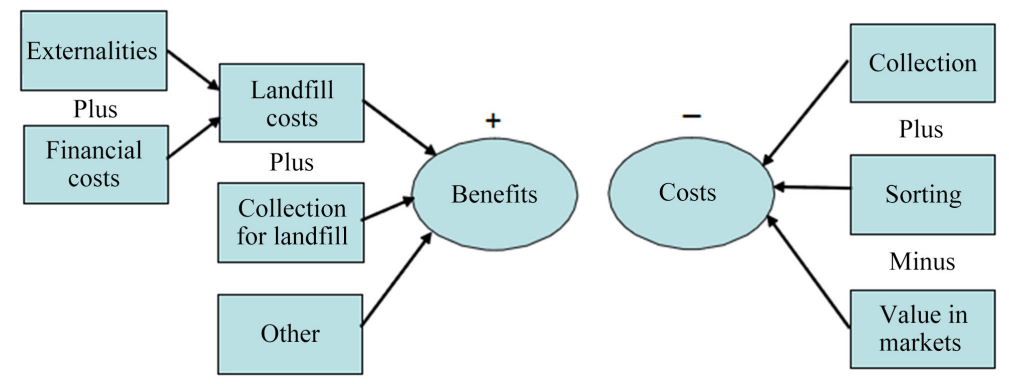

Figure 1. Components of the recycling analysis.

Compliance with EU targets on collection, recycling and landfill diversion will remain high priority and some Member States will have to make strenuous efforts to meet EU targets.

\subsection{Current Economic Development and Recycling}

Economic development is a key driver of environmental degradation, as the treadmill of production theory [20]. Affluent countries, regardless of their current state of higher development, are not developing as fast as the less affluent nations. Global researchers suggest that more affluent nations are being able to externalize part of the degradation caused by consumption and production to less affluent countries. Although degradation is of levelled importance in all countries, affluent nations experienced the same growth rates in degradation as less affluent countries. It seems that GDP growth positively affects individual-level environmental concerns [20].

Cities, as engines of economic growth and social development, require large quantities of natural resources to meet their inhabitants' economic and social needs [21]. Good infrastructure and reliable service provision are key elements to reach sustained cities' development. In this regard, investment opportunities and service access to vulnerable populations are being enhanced.

In response to the lack of sanitation infrastructure, many governments, development agencies and Non-Governmental Organizations (NGOs), usually implement programmes to provide latrines to poor and vulnerable populations. These programmes often do not link infrastructure provision with its necessary management requirements. As a result, the majority of "latrine-based" cities do not have a reliable solution for emptying latrines, and for faecal sludge and wastewater transportation and treatment. Once these infrastructures are available, they are disconnected from business opportunities that use resources such as water, nutrients or biosolids for their productive activities. This lingering failure in sanitation is putting a huge financial burden on municipalities that have to rely on permanent subsidies to operate and maintain infrastructures. The recent WHO guidelines on the safe use of wastewater, excreta and greywater [22], allow reuse alternatives besides agricultural irrigation. Therefore, we're leading to a new paradigm which is urban sanitation management needs linkage with cities' economic development agenda. 
Since 1990s, waste recycling became a basic element of the sustainable development. However, recycling flow modeling analysis shows that is inefficient to perform the necessary "decoupling" of economic development and the depletion of non-renewable raw materials [23]. Natural resource depletion of raw material is inevitable when global consumption grows by more than $1 \%$ per annum. Recycling could slow down the tendency for some years or decades at best. Decoupling the economy and its material needs must be perceived as a double decoupling, the two components of which have to be inoperative if they are implemented separately. Only the combination of the two makes a significant impact on the problem of resources: 1) A fundamental decoupling, namely to restrain the growth of total consumption of raw material (virgin or recycled) 2) A relative decoupling to reduce, through recycling and reuse, the share of primary resources (virgin) in the total production of raw material.

In this perspective, the actual role of recycling to protect the resources is not significant for non-renewable materials which consumption tends to grow more than $1 \%$ per year [23]. Conversely, once the fundamental decoupling is performed by other means, so that the growth of total consumption of raw materials is reduced below $1 \%$ per year, recycling becomes indispensable if the rate of effectiveness is very high globally. Only recycling rates above $80 \%$ lead to a significant slowdown of natural resources depletion.

In conclusion, sustainable development policies cannot rely primarily on recycling, even though it is an important component. These policies should primarily aim at reducing the consumption of each non-renewable raw material so that the annual growth rate remains under $1 \%$. And in any case, to be efficient as the indispensable second part of these policies, recycling should be developed to much higher rates than the ones observed for most recycled materials in the world today.

\subsection{Recycling in Industries}

Recycling brings in the foreground mainly short-lasting consumer goods from households [24]. Industries, however, due to increasing prices of raw materials are laid great emphasis on overall operational costs and are oriented even more towards sustainability practices during the recent decades. As a result of sustainable "green policies" large quantities of different origin "wastes" are reused as secondary raw materials in their production processes.

Driving forces for recycling are, for instance, the high purchase value of noble metals like gold and platinum with manifold appliances in modern industry, the scarcity of certain technologically important elements like tungsten and rare earth, the energy saving in production processes like those for aluminum, steel, glass and paper and the avoidance of unsustainable impacts to the environment such as the utilization of coal ash in cement industry and re-integration of demolition waste. In all cases, energy use and secondary material production are closely coupled, even when, in cases like gold recovery, the amount and cost of 
energy used are economically not the most important target [25] [26].

There are numerous industrial recycling processing routes, which are already in full swing in building and minerals industries, in pulp and paper processing and in many non-ferrous metallurgical industries [27]. Industries of plastics and glass processing are also in high demand of recycling, so are wooden pallets industries. Consequently, all manufacturing industries, such as automotive industries, are affected.

\subsection{International Trade and Recycling}

The international trade of waste products is remarkable and has grown even more in the past decade. Already in the distant 2007, were traded globally more than 191 million tons of waste [28].

Domestic wastes and Domestic economy are defined and considered to be interrelated through three potential dealing alternatives. 1) recycling; 2) exportation to other countries; 3 ) disposal. Recycled material is redirected back to the Domestic Economy to be reprocessed or to be consumed. However, few waste products are $100 \%$ recyclable. Some waste currents, inevitably end up back in the domestic waste stream either to be recycled once more (possibly for different recyclable components), to be exported or disposed-off domestically.

In most countries, waste domestically disposal, involves a combination of landfill or incineration. Nonetheless, countries with lax environmental regulations turn a blind eye to environmentally detrimental actions, such as direct waste disposal to the environment. Waste is exported for two possible reasons: to be recycled for materials in the foreign country-destination or to achieve energy recovery or even to be disposed of.

The empirical approach to estimate the effect of environmental regulation differences on waste trade is based on the gravity model.

\subsection{Employment and Recycling}

Recycling nowadays appears to be functioning on industrial basis which reduces the waste disposal and thereof natural resource consumption and energy efficiency improvement. As a result, it sustains an economic and business interest for entrepreneurs all over the world. The EU held a 50\% world tonnage share of the waste and recycling industries. EU eco-industries sector gained a turnover of around 227 billion $€$, corresponding to $2.2 \%$ of EU GDP in 2007. This includes waste treatment (€52 billion) and recycling (€24 billion, over 500,000 jobs). The recycling sector is made up of over 60,000 companies; the profile of which is categorized into the following percentages i.e. 3\% large; $28 \%$ medium; $69 \%$ small [29].

\section{Reuse}

\subsection{Economic Approaches on Reuse (Recovery)}

The article 3 of the 2008 European Waste Framework Directive (2008/98/EC) 
[30], defines reuse as "any operation by which products or components that are not waste are used again for the same purpose for which they were conceived (i.e. dealing with waste prevention)". There is also the concept of preparing for reuse, which is "checking, cleaning or repairing recovery operations, by which products or components of products that have become waste are prepared so that they can be re-used without any other pre-processing".

The EU's current waste policy is based on the "waste hierarchy". Reuse (upper pyramid level), is a much more desirable option than recycle (lower pyramid level). Reuse differs from Recycle in the sense that there is no need in changing the physical properties of the material. Consequently, reuse is energy effective in contrast with the recycle [31].

For the past four decades, economists have primarily investigated recycling. However, relatively a few studies have been published so far on the economics of reuse. In one of the most recent studies, a model of reuse was developed based on durable goods theory [32]. Given the fact that consumers vary in their valuations for used goods, he points out that a waste amount is minimized when there is a second-hand market. When many consumers begin to reuse, welfare of consumers who do not buy used goods will be improved.

Waste \& Resources Action Programme [33], has developed a specific methodology for quantifying the impacts of reusing products. The methodology is based on best practices in life cycle assessment and cost-benefit analysis [34], and also provides guidance on sourcing data for the model. The key characteristics of the methodology include guidance on:

- system boundaries;

- product lifetimes and displacement effects of reuse;

- allocation of environmental or economic impacts to different parts of the supply chain;

- use of costs and prices;

- job and labor costs.

A comprehensive tool-supported model has been proposed [35], for estimating, predicting, and analyzing the costs of software reuse. Their premise lies in four decisions that arise in the practice of software reuse:

- whether to introduce reuse in the practice of software development;

- whether to initiate a domain analysis/domain engineering initiative;

- whether to introduce reuse practices for a specific development project;

- whether it is worthwhile to develop a specific component to serve a group of project teams.

All these decisions can be quantified in economic terms, and modeled as investment decisions; consequently, their economic rationality can be quantified by traditional investment analysis functions.

Reuse has some certain potential environmental and socio-economic advantages:

- It reduces the amount of waste. Thus, disposal needs (incrimination and landfilling) and relative costs are reduced, too. 
- It reduces the amount of $\mathrm{CO}_{2}$ emissions. A case study of [36] revealed that T-shirt reusing in the UK saved 450.000 tones $\mathrm{CO}_{2}$ equivalents per year.

- Over the period 1985-2000, computer lifespan (purchase to disposal) decreased steadily from a mean of 10.7 years in 1985 to 5.5 years in 2000 [37]. The average lifespan of contemporary electric and electronic appliances, keep decreasing over the years, so there is an increasing proportion of energy efficient appliances which are discarded, often still in functioning order.

- Reuse is labor intensive as it involves collection, sorting, testing, refurbishment and reselling. Computer reuse creates 296 more jobs for every 10,000 tons of material disposed of each year [38].

- There's a noticeable part of consumers, who are positive about buying used products. According to a Flash Eurobarometer survey [39], almost 7 in 10 (68\%) EU citizens said that they were willing to buy certain items secondhand, such as furniture, electronic equipment or textiles.

Disadvantages are also apparent:

- Reuse often requires checking, cleaning and/or transport, actions that have both financial and environmental costs.

- The philosophy of reusing a product must be embedded in the designing and manufacturing process [40]. On the same wavelength, the UK Government Sustainable Development Strategy [41], mentions that more than $80 \%$ of all product-related environmental impacts are determined by product design.

- Reusable products need to be more durable and reliable than single-use products, as well as easy to upgrade.

- Practical applications of reuse are not yet widely known.

\subsection{Benefits and Costs of Reuse}

The reuse of waste is primarily a very effective utilization of resources. Thus, it is possible to produce new products at a relatively low cost. On the other hand, reuse applications are limited because practical procedures are not yet widely known as mentioned above or practiced in many countries.

A very promising implementation of reuse is in handling demolition waste. According to Eurostat [8], construction activity within EU has increased substantially in the past decade. The demolition and renovation of old buildings have led to an equivalent increase in construction and demolition waste. This kind of waste reaches approximately $33 \%$ of all waste generated in the EU and due to its composition (concrete, bricks, metals, excavated soil etc.), there is a significant potential to reuse and/or recycle.

Applications of Recycled Aggregate Concrete (RAC) [42], were introduced, which were produced by crushing waste concrete. Small pieces of concrete can be used as gravel for new construction projects like pavements and highways, while larger pieces of crushed concrete, such as riprap, can be used in shoreline structures, seawalls for erosion control.

As far as building materials concerns, the reuse of industrial sludge as pelletized aggregate for concrete was proposed [43]. A copper slag recycling plant 
generates 100 metric tons of slag per day, which usually ends up in landfills. The experimental results indicated that a complete replacement of conventional aggregates with sintered sludge pellets for structural concrete is both technically and environmentally feasible.

As far as the construction industry concerns, it is obvious that reuse could be an alternative source for raw material. It is not clear though, whether reuse is each case cost-efficient, nonetheless, it is important to bear in mind that reuse practices are still in progress.

Greywater reuse in one more interesting application. The benefits of reusing city wastewater for agricultural purposes can far outweigh the costs involved and reduce overall demand for freshwater, according to a recent study [44]. The researchers calculated that the total benefits to agriculture and a city of a reuse project in Spain outweighed the total costs by $€ 9.5$ million per year.

Additionally, greywater reuse can reduce the investment in new water headworks for water abstraction and treatment, distribution networks and new sewerage investment by substituting treated wastewater for non-potable applications and thereby increasing the availability of potable water. Meeting growing demand for water resources, (especially in urban areas), may require the development of additional large-scale water resources and associated infrastructure. By meeting some of this demand, through treated wastewater reuse and efficiency improvement, additional infrastructure requirements and the resulting financial and environmental impacts can be reduced or, in some cases, eliminated altogether [45].

\subsection{Competitiveness and Reuse}

A correlation was noticed [46] between social/environmental performance and financial performance, which indicates potential business benefit. From a Corporate Strategy Perspective suggested [47] that a corporation should not only be innovative, but also create distinctive value for the society. As a consequence, by practising strategic Corporate Social Responsibility, a company can be more competitive. Environmental concerns are a vital part of (CSR) and Corporate Sustainability (CS), and towards being "green", many contemporary multinational companies have embraced 3R's practices i.e. (Reduce-Reuse-Recycle).

Technology, computer and peripherals industries often have reuse and recycle programs in order to recover and recycle or reuse used products. By reusing or recycling, companies try to produce waste-free products (zero waste to landfill) and reduce among others their carbon footprint.

Within the framework of sustainable development, companies like Xerox aim in maximizing the end-of-life potential of products and components by considering reuse in the overall design process [48]. Machines are designed in such a way to be easier to be disassembled. Thereof they contain fewer parts that are easy to reuse or recycle. Parts are durable designed for multiple product life cycles. As a result, reusing is applicable to $70 \%-90 \%$ of machine components (by weight). 
In a manufacturing point of view, producing families of products has a positive effect on reusing, since a family of products shares common parts. Additionally, products whose designs are based on previous models may have $60 \%$ of their parts by weight in common with previous equipment. The practice of reusing parts reduces the amount of raw material needed to manufacture new parts, which generates a significant amount in cost savings each year, in addition to energy savings.

\subsection{Hotelling Approach}

\subsubsection{The Framework}

The problem that emerges involves the option to be adopted between e.g. quick biomass exploitation and biomass selling price. Monopolies, duopolies and perfect competition are all reflections of the market spectrum. This palette of market functioning undertakes the responsibility for the quick exploitation of irreplaceable resources, such as biomass, thus great concern has been grown of the upcoming dilemma, whether to control or not all market variations.

At first glance, it seems that biomass exploitation can never be too slow for the public good. Undoubtedly, for every proposed rate of biomass production there will be the upper limit to the ultimate exhaustion.

Considering that the total supply is not to be reserved for our remote descendants and that there is an optimum rate of present production, then the tendency of monopoly and partial monopoly is to keep production below the optimum rate and to exact excessive prices from consumers.

Certain technical conditions, most pronounced in the biomass industry, lead to great wastes of material and expensive competitive drilling, losses which may be reduced by systems of control that involve delay in production.

\subsubsection{Biomass in Free Competition Market}

Since it is indifferent to the owner of biomass, whether he receives for a unit of his biomass a current price $P_{o}$, or a price $\left(P_{o} * e^{\gamma * t}\right)$, after time $t$, it is not unreasonable to be considered that the price $P$ will be a function of the time of the exponential form:

$$
P(t)=P_{o} * e^{\gamma * t}
$$

where ( $\gamma$, a parameter).

In that case, the various units of the biomass are to be regarded as equally valuable at any time, except for the varying costs of placing them upon the market. The lower price determines the accessibility order. Should interest rates or degree of impatience vary among the biomass owners, it will also affect the order of extraction.

Given that $P$ denotes the net price received after payment of the cost of extraction and market placing the formula regulates the relative prices at different times under free competition. The absolute level, or the value $P_{o}$ of the price at $t=0$ reference line, is dependent upon demand and the total biomass supply. The simple demand function is given as follows: 


$$
q=a-b * P
$$

where $q$ the quantity of product, $P$ the price of the product, $b$ the coefficient of slope and $a$ the function constant.

For a fixed demand curve, a question arises, whether the time until exhaustion will be finite or infinite turns upon whether a finite of infinite value of $P$ will be required to provoke $q$ elimination. All biomass will be exhausted in a finite time. If the exploitation will continue forever, even at a gradually diminishing rate, the demand function will be rewritten as:

$$
q=e^{-b * p}
$$

In general, the higher the price anticipated when the rate of production becomes extremely small, compared with the price for more rapid production, the more protracted will be the period of operation.

\subsubsection{Maximum Social Value and State Interference}

From static economic analysis standpoint, in perfect competition market, where the industrial factors are simplistic, there will be a certain tendency towards total benefit maximization.

There are in extractive industries discrepancies in perfect markets, which are leading to particularly wasteful forms of exploitation though they might be well regulated for the public interest. Waste production could be susceptible to biomass turning point new techniques that might give rise to sharp biomass increment to be handled.

\subsection{EU Legislation and Reuse}

Waste management policy in EU is driven by a number of EU Directives, the most important of which is the revised Waste Framework Directive 2008 (rWFD), and emerging EU policies on resource efficiency [30]. This provides the overarching legislative structure which forms the basis for waste legislation in each Member State and sets baseline future targets and objectives for the local industry. The above incorporated the waste hierarchy to promote waste prevention, a practice that entails more recycling and better use of resources, along with protecting measurements for our health and the environment.

Waste Electrical and Electronic Equipment (WEEE) Directive (2002/96/EC), which promotes the collection and recycling of electric and electronic equipments/devices have been set in force since February 2003. The legislation promotes the creation of collection schemes where consumers return their used e-waste free of charge. The objective of these schemes is to encourage recycling increment and/or re-use of such products [49].

Two major EU Directives refer to wastewater re-use. The first one is The Urban Wastewater Treatment Directive (91/271/EEC). Article 12 explicitly denotes that "treated wastewater shall be reused whenever appropriate" under the requirement of "minimizing the adverse effect on the environment" [50]. The second one is the Water Framework Directive (WFD) (2000/60/EC), which re- 
fers, under Annex VI (v) clause, to "emission controls" and under Annex VI(x) to "efficiency and reuse measures, inter alia, promotion of water efficient technologies in industry and water saving techniques for irrigation", as two, nonexclusive, supplementary measures [51].

\section{Conclusions}

The above-given manuscript demonstrates a comprehensive analysis of certain economic models addressed to environmental issues. The analysis was focused on waste management, and specifically on the process of the recycle and reuse.

Recycle is an established practice in many countries, while reuse is still under development. Reuse is a more desirable option, as far as waste management concerns, and EU legislation seems to encourage this practice. Many industries, especially in the technology section, have developed recycle and reuse programs in order to gain an advantage, while some of them have set a target of zero waste in their production process. Hoteling concept and biomass market exploitation, mostly in underdeveloped countries, is a great concern of new waste management practices. Waste hierarchy and action programmes develop a methodology for quantifying reuse products and their impact. CBA analysis mechanisms were adopted for environmental evaluation when related to the economy.

\section{Conflicts of Interest}

The authors declare no conflicts of interest regarding the publication of this paper.

\section{References}

[1] Scorse, J. (2010) What Environmentalists Need to Know about Economics. Palgrave Macmillan, New York. https://doi.org/10.1057/9780230114043

[2] Pearce, D., Atkinson, G. and Mourato, S. (2006) Cost-Benefit Analysis and the Environment, Recent Developments. OECD Publishing, Paris.

[3] DSM Environmental (2009) Recycling Economic Information Study Update: Delaware, Maine, Massachusetts, New York, and Pennsylvania. Final Report. Northeast Recycling Council Inc., Brattleboro, USA.

[4] Stavins, R.N. (2003) Experience with Market-Based Environmental Policy Instruments. In: Mäler, K.-G. and Vincent, J.R., Eds., The Handbook of Environmental Economics, Vol. I, Elsevier Science, Amsterdam, 355-435.

https://doi.org/10.1016/S1574-0099(03)01014-3

[5] Nordhaus, W.D. and Tobin, J. (1972) Is Growth Obsolete? In: Nordhaus, W.D. and Tobin, J., Eds., Economic Research: Retrospect and Prospect, Vol. 5, National Bureau of Economic Research, Cambridge, 1-80.

https://www.nber.org/system/files/chapters/c7620/c7620.pdf

[6] Daly, H.E. and Cobb Jr., J.B. (1989) For the Common Good: Redirecting the Economy toward Community, the Environment, and a Sustainable Future. Beacon Press, Boston.

[7] Cobb, C.W. and Cobb, J.B. (1994) The Green National Product: A Proposed Index of Sustainable Economic Welfare. University Press of America, Lanham. 
[8] Fischer, C. and Werge, M. (2009) EU as a Recycling Society. ETC/SCP Working Paper 2/2009, European Environmental Agency, Copenhagen.

[9] Banerjee, S., Aditya, G. and Saha, G.K. (2013) Household Disposables as Breeding Habitats of Dengue Vectors: Linking Wastes and Public Health. Waste Management, 33, 233-239. https://doi.org/10.1016/j.wasman.2012.09.013

[10] Eurostat (2010) Environmental Statistics and Accounts in Europe. Eurostat Statistical Books, Publications Office of the European Union, Luxemburg.

[11] Owen, N., Mayne, B. and Maunder, A. (2012) Professional Perspectives on Waste and Resource Management. The Chartered Institution of Waste Management. Chartered Institution of Wastes Management, Northampton.

https://www.ciwm.co.uk/Custom/BSIDocumentSelector/Pages/DocumentViewer.as px?id=QoR7FzWBtisamYEcWSfL6SxAJRLAPT9voNQWYgqgLJHA33jKXnEZNfy2 bcrDUXe4UJKrkOYdK0FSkir93AXPt19SFM5EF8le\%252ftvvqDbDL8HzUCxYAPcz \%252fKPYT\%252fSkSb1yntDlZAOcCibWjt86c4KyzGzEsTrESVpfBwdcN58Pr4wNJ h3ql2qqrFFZT2ek8wBElkGpcEvLU7BOdrGTiv\%252bQfg\%253d\%253d

[12] International Organization for Standardization (2016) ISO 14021:2016, Environmental Labels and Declarations-Self-Declared Environmental Claims (Type II Environmental Labelling). https://www.iso.org/standard/66652.html

[13] Nakatani, J. and Hirao, M. (2011) Multicriteria Design of Plastic Recycling Based on Quality Information and Environmental Impacts. Journal of Industrial Ecology, 15, 228-244. https://doi.org/10.1111/j.1530-9290.2010.00316.x

[14] Dahmus, J.B., Fredholm, S.A., Olivetti, E.A., Gregory, J.R. and Kirchain, R.E. (2008) Modeling the Economic and Environmental Performance of Recycling Systems. 2008 IEEE International Symposium on Electronics and the Environment, San Francisco, 19-22 May 2008, 1-6. https://doi.org/10.1109/ISEE.2008.4562896

[15] Guerrero, L.A., Maas, G. and Hogland, W. (2013) Solid Waste Management Challenges for Cities in Developing Countries. Waste Management, 33, 220-232. https://doi.org/10.1016/j.wasman.2012.09.008

[16] Lavee, D. (2007) Is Municipal Solid Waste Recycling Economically Efficient? Environmental Management, 40, 926-943. https://doi.org/10.1007/s00267-007-9000-7

[17] Hanley, N. and Slark, R. (1994) Cost-Benefit Analysis of Paper Recycling: A Case Study and Some General Principles. Journal of Environmental Planning and Management, 37, 189-197. https://doi.org/10.1080/09640569408711969

[18] European Parliament and the European Council (2006) Regulation (EC) No 1907/2006 of the European Parliament and of the Council of 18 December 2006, Concerning the Registration, Evaluation, Authorisation and Restriction of Chemicals (REACH), Establishing a European Chemicals Agency, amending Directive 1999/45/EC and Repealing Council Regulation (EEC) No 793/93 and Commission Regulation (EC) No 1488/94 as well as Council Directive 76/769/EEC and Commission Directives 91/155/EEC, 93/67/EEC, 93/105/EC and 2000/21/EC.

[19] European Council (1999) Council Directive 1999/31/EC of 26 April 1999 on the Landfill of waste. Official Journal, No. L 182, 1-19.

[20] Givens, J.E. and Jorgenson, A.K. (2011) The Effects of Affluence, Economic Development, and Environmental Degradation on Environmental Concern: A Multilevel Analysis. Organization \& Environment, 24, 74-91. https://doi.org/10.1177\%2F1086026611406030

[21] Koné, D. (2010) Making Urban Excreta and Wastewater Management Contribute to Cities' Economic Development: A Paradigm Shift. Water Policy, 12, 602-610. https://doi.org/10.2166/wp.2010.122 
[22] World Health Organization (2006) Excreta and Grey Water in AgricultureGuidelines for the Safe Use of Wastewater, Excreta and Greywater Use. Vol. 4, World Health Organization, Geneva.

[23] Grosse, F. and Mainguy, G. (2010) Is Recycling "Part of the Solution"? The Role of Recycling in an Expanding Society and a World of Finite Resources. Open Edition, S.A.P.I.EN.S, 3, 1-17.

[24] Reh, L. (2006) Challenges for Process Industries in Recycling. China Particuology, 4, 47-59. https://doi.org/10.1016/S1672-2515(07)60234-6

[25] Hatayama, H., Daigo, I., Matsuno, Y. and Adachi, Y. (2009) Assessment of the Recycling Potential of Aluminum in Japan, the United States, Europe and China. Materials Transactions, 50, 650-656. https://doi.org/10.2320/matertrans.MRA2008337

[26] Miranda, R. and Blanco, A. (2010) Environmental Awareness and Paper Recycling. Cellulose Chemistry and Technology, 44, 431-449.

[27] Gaines, L. (2004) Recycling of Paper. In: Cleveland, C.J., Ed., Encyclopedia of Energy, 1st Edition, Elsevier, 253-260. https://doi.org/10.1016/B0-12-176480-X/00380-6

[28] Kellenberg, D. (2012) Trading Wastes. Journal of Environmental Economics and Management, 64, 68-87. https://doi.org/10.1016/j.jeem.2012.02.003

[29] European Commission (2007) Report of the Taskforce on Recycling, Composed in Preparation of the Communication, "A Lead Market Initiative for Europe". http://ec.europa.eu/enterprise/policies/innovation/policy/lead-market-initiative/file s/recycling_taskforce_report_en.pdf7

[30] European Union (2008) Directive 2008/98/EC of the European Parliament, Waste and Repealing Certain Directives. Official Journal of the European Union, No. L 312, 3-30.

https://eur-lex.europa.eu/legal-content/EN/TXT/PDF/?uri=CELEX:32008L0098\&fr $\underline{\mathrm{om}=\mathrm{EN}}$

[31] European Commission (2011) Report from the Commission to the European Parliament, the Council, the European Economic and Social Committee and the Committee of the Regions-On the Thematic Strategy on the Prevention and Recycling of Waste.

http://eur-lex.europa.eu/LexUriServ/LexUriServ.do?uri=COM:2011:0013:FIN:EN:P $\underline{\mathrm{DF}}$

[32] Yokoo, H.F. (2010) An Economic Theory of Reuse. Sustainability Science, 5, Article No. 143. https://doi.org/10.1007/s11625-009-0091-3

[33] Waste and Resources Action Programme (2011) A Methodology for Quantifying the Environmental and Economic Impacts of Reuse. Waste and Resources Action Programme, Banbury.

[34] Denne, T., Irvine, R., Atreya, N. and Robinson M. (2007) Cost Benefit Analysis. Prepared for Ministry of the Environment. Covec Ltd., Auckland.

[35] Mili, A., Chmiel, S.F., Gottumukkala, R. and Zhang, L. (2000) An Integrated Cost Model for Software Reuse. Proceedings of the 22nd International Conference on Software Engineering, Limerick, June 2000, 157-166. https://doi.org/10.1145/337180.337199

[36] Waste and Resources Action Programme (2011) Benefits of Reuse, Case Study: Clothing. Waste and Resources Action Programme, Banbury.

[37] Babbitt, C.W., Kahhat, R., Williams, E. and Babbitt, G.A. (2009) Evolution of Product Lifespan and Implications for Environmental Assessment and Management: A 
Case Study of Personal Computers in Higher Education. Environmental Science \& Technology, 43, 5106-5112. https://doi.org/10.1021/es803568p

[38] United Nations Industrial Development Organization (2009) Reuse and Recycle: Growing Green Business.

https://www.unido.org/sites/default/files/2010-03/0_Green_busines_0.PDF

[39] The Gallup Organization (2011) Attitudes of Europeans towards Resource Efficiency, Flash No 316. The Gallup Organization, Hungary.

[40] Cooper, T. (2010) Longer Lasting Products: Alternatives to a Throwaway Society. Gower Publishing Ltd., Surrey.

[41] Secretary of State for Environment, Food and Rural Affairs (2005) Securing the Future, Delivering UK Sustainable Development Strategy. Department for Environment, Food \& Rural Affairs. Stationery Office Limited., London.

[42] Li, X. (2008) Recycling and Reuse of Waste Concrete in China: Part I. Material Behaviour of Recycled Aggregate Concrete. Resources, Conservation and Recycling, 53, 36-44. https://doi.org/10.1016/j.resconrec.2008.09.006

[43] Tay, J., Hong, S. and Show, K. (2000) Reuse of Industrial Sludge as Pelletized Aggregate for Concrete. Journal of Environmental Engineering, 126, 279-287. https://doi.org/10.1061/(ASCE)0733-9372(2000)126:3(279)

[44] Heinz, I., Salgot, M. and Mateo-Sagasta Dávila, J. (2011) Evaluating the Costs and Benefits of Water Reuse and Exchange Projects Involving Cities and Farmers. Water International, 36, 455-466. https://doi.org/10.1080/02508060.2011.594984

[45] Cogoy, M. (2009) A Model of Eco-Efficiency and Recycling. Economics, 3, 1-30. https://doi.org/10.5018/economics-ejournal.ja.2009-21

[46] Orlitzky, M., Schmidt, F.L. and Rynes, S.L. (2003) Corporate Social and Financial Performance: A Meta-Analysis. Organization Studies, 24, 403-441. https://doi.org/10.1177\%2F0170840603024003910

[47] Porter, M.E. and Kramer, M.R. (2006) Strategy \& Society: The Link between Competitive Advantage and Corporate Social Responsibility. Harvard Business Review, 84, 78-92, 163.

[48] Xerox (2009) Nurturing a Greener World through Sustainable Innovation and Development. 2010 Report, Xerox, Norwalk.

[49] European Union (2012) Directive 2012/19/EU of the European Parliament and of the Council, "Waste Electrical and Electronic Equipment (WEEE)". Official Journal of the European Union, No. L 197, 38-71

https://eur-lex.europa.eu/legal-content/EN/TXT/PDF/?uri=CELEX:32012L0019\&fr om=EN

[50] European Economic Community (1991) Council Directive, (91/271/EEC), Concerning Urban Waste Water Treatment. Official Journal of the European Communities, No. L 135, 40-91.

https://eur-lex.europa.eu/legal-content/EN/TXT/PDF/?uri=CELEX:31991L0271\&fr $\underline{\mathrm{om}=\mathrm{EN}}$

[51] European Commission (2000) Directive 2000/60/EC of the European Parliament and of the Council "A Framework for Community Action in the Field of Water Policy”. Official Journal of the European Union, No. L 327, 1-73. 